\title{
Safe Surgery Saves Lives - An Appraisal Of The Who Initiative
}

\section{N. Ananthakrishnan *}

Surgical procedures have the inherent capacity to cause unintended harm to the patient if performed without due care. It is the very nature of the specialty which by its invasiveness carries the risk of causing major or minor morbidity and sometimes even mortality.

The factors which may contribute towards adverse effects during surgical procedures are:

- Involvement of multiple personnel

- Residents in wards (who do the workup and pre-op orders)

- Nurses in the wards( who are responsible for carrying out the pre-op orders)

- Attenders (transport to and from the operating rooms)

- OR - nurses, technicians, surgeons, anesthesiologists

- Ancillary departments- Pathology and other laboratories which contribute to patient management

- Frequent change of personnel contributes to the possibility of errors since everyone assumes that someone has carried out the required instructions and occasionally no one really has.

\section{MAgNitude OF THE PROBLEM:}

It has been estimated that the global volume of surgery amounts to 187-281 million procedures annually or approximately 1 per 25 human beings (1). The rate of complications varies from 3-22\% in different countries. Half of these contributions are considered to be preventable (2). Taking an average death rate of $0.5 \%$ due to these complications (although the death rate varies from $0.4-0.8 \%$ in developed countries and 5-10\% in developing countries), over one million patients die annually directly due to the consequences of surgery (2).

It has been estimated that this represents 164 million DALY (Disability adjusted life years) or about $11 \%$ of the entire disease burden due to surgical causes (3). Gawande mentions that in USA alone, each American has approximately 7 operations in his life time. This amounts to 50 million operations per year and accounts for 150,000 deaths annually (2).

There is, therefore, a crying need for attention to this matter and for steps which can reduce the potential harmful effects of surgery.

Previous work:

The major reason why errors occur in the process of surgical management is due primarily to two reasons, viz. the complexity of the task and the difficulty of remembering to carry out all necessary activities relying on memory alone. It has been mentioned that the levels of cognitive function are often compromised with increasing levels of stress and fatigue(4).It is a logical corollary of this realisation that having a checklist of things to do would contribute to avoiding errors.

Several attempts have been made successfully in the past which have demonstrated that institution of checklists has improved the functioning of health care providers.

Pronovost in Johns Hopkins in 2001 instituted a five item checklist to reduce the morbidity of placement of central lines. The items were

i. Washing hands before the procedure

\footnotetext{
* Prof. N. Ananthakrishnan, Professor of Surgery

MGMCRI, Pondicherry
} 
ii. Cleaning skin with an antiseptic

iii. Using sterile drapes

iv. Wearing masks / sterile gowns / gloves

v. Placing sterile dressing on the wound after the procedure.

These measures reduced the ten day infection rate from 11 to $0 \%$. It was estimated that 43 infections and 8 deaths were prevented by this measure in just one hospital (5).

Even for the lay public, simple measures to jog the memory have contributed significantly in reducing health care morbidity. Luby et al in an experiment in Karachi, Pakistan, insisted on washing hands with soap prior to

i. Washing themselves

ii. After defecation

iii. Before handling an infant

iv. Before eating

v. Before serving others $35 \%(6)$.

This simple measure reduced the incidence of diarrhea in children by $52 \%$, pneumonia by $48 \%$ and impetigo by

Offering incentives for improving care has been tried without much success. Lindenauer et al published the results of their study on the pay for performance scheme in the USA. Using changes in adherence to 10 individual and 4 composite measures of quality, they compared public reporting data of 207 pay for performance hospitals with 406 others who indulged only in public reporting of data. It was found that pay for performance resulted in improvement in only $2.6-4.1 \%$ over two years (7).

\section{RISKS IN SURGERY:}

There are four major risks in surgical procedures. These are:

i. Infection

ii. Bleeding

iii. Anesthetic problems

iv. Unexpected complications such as

a. excess bleeding,

b. un-expected pathology

c. Retained surgical instruments, sponges etc.

Any measure which seeks to reduce the complications of surgery must address these issues. In addition there are two very important aspects which are exceedingly significant. These are communication and team work.

\section{IMPORTANCE OF COMMUNICATION AND TEAM WORK:}

Research reveals a pressing need to develop a better understanding of those social behaviors and cognitive skills that are needed by individual members of an operating tem to ensure safe and efficient surgical performance (8). Communication is acknowledged as a key component of team performance but in surgery, it is often assumed to be a desirable and inherent attribute rather than being regarded as an important and acquired clinical skill which may need to be applied with care (9).

Lack of continuous communication between various healthcare personnel can result in actions which can have adversarial consequences as demonstrated by a study by Burda et al (2005). Review of case records in 79 patients showed discrepancies between surgery and anesthesiology preoperative medication histories in $73 \%$ of patients;

a. $23 \%$ had different allergy information

b. $56 \%$ had different preoperative medication and

c. $43 \%$ had different doses of drugs

In other studies it was shown at Johns Hopkins, that improved OR briefing resulted in decrease in wrong site 
operations (11). At Toronto General Hospital, it was shown that getting teams to talk by use of a 21 item check list improves communication in the operating room. (12).The group had earlier shown that communication breaks occurs in approximately $30 \%$ of cases in the OR of which one third jeopardize patient safety (13).

Mazocco et al the Sharp Health Center in California conducted a study using a standardized instrument to assess team behavior(14). They did a retrospective chart review to measure 30 day outcomes after adjusting for ASA scores. It was found that the odds of complications or death in operated patients increased if the following behaviors were exhibited less frequently

- Information sharing during intra-op. phase

- Briefing during handoff phase

- Information sharing during handoff

\section{THE WHO INITIATIVE:}

It is in this background that the WHO initiated a move to make surgery safer. The following material is drawn from the WHO publication - "WHO Guidelines for Safe Surgery, 2009, Safe Surgery Saves Life" and is largely a summary of the same. The team was led by Atul Gawande of Harvard, University, USA. The findings of the team were published subsequently in the New England Journal of Medicine (15).

The problems visualized by the team included the fact that surgical safety was a complex issue. Surgical safety was yet to be recognized as a significant public health problem, data was sparse, even existing safety practices were not uniformly applied and there was lack of resources.

They felt that essentially there were three areas which required to be addressed. These were:

- Prevention of SSI by

- Hand washing

- Appropriate use of antibiotics

- Antiseptic skin preparation

- Atraumatic wound care

- Instrument decontamination and sterility

- Establishing safety of Anesthesia by ensuring

- Presence of a trained anesthetist

- Anesthesia machine and medication safety checks

- Pulse oximetry, heart rate monitoring

- Blood Pressure monitoring

- Temperature monitoring

- Establishing safe surgical teams by

- Improved communication

- Ensuring correct patient site and procedure

- Informed consent

- Availability of all team members

- Adequate team preparation and planning for the procedure

- Confirmation of patient allergies

The approach of the WHO team was to disseminate information on role and pattern of surgical morbidity and safety measures, define minimum set of uniform measures for surveillance, identify simple set of surgical safety standards by employing checklists and Testing / improving checklists by pilot study. Besides it was felt that the recommendations to ensure the above should be simple, widely applicable and measurable.

The WHO team considered the following as their principal objectives:
A. Objective I - operate on correct patient, correct site by
a. Verification
b. Marking
c. Checking before surgery 
B. Objective II -Measures to reduce harm from anesthesia and protect from pain by attention to

a. Equipments

b. Gas supplies

c. Monitoring

d. Ancillary equipment and medication

e. Instruments (supplies and standards

C. Objective III - Recognize and effectively prepare for life threatening loss of airway or respiratory function by

a. Airways assessment

b. Airways management

c. Aspiration of gastric contents

D. Objective IV- Recognize and effectively prepare for risk of high blood loss by

a. Considering probability of blood loss

b. Preparing adequately

c. Managing optimally

E. Objective V - avoid inducing allergic / adverse drug reaction for which patient is known to be at significant risk

F. Objective VI - consistently use methods known to reduce risk of Surgical site infection

G. Objective VII - Prevent inadvertent retention of instruments and sponges in the surgical wound

H. Objective VIII - Secure and accurately identify all surgical specimens

I. Objective IX - Effectively communicate and exchange critical infection for the safe conduct of the operation using checklists to improve communication

J. Objective $\mathbf{X}$ - Hospital and public health systems will establish routine surveillance of surgical capacity / volume / results. These should include considerations of

a. No. of surgeons, anesthetists, nurses, para-medicals

b. Infrastructure

c. Economic considerations

d. Positive incentives

e. Negative incentives

f. Case mix and risk adjustment

Based on the success of checklists in earlier efforts in improving patient care, the team decided to adopt the checklist approach. A nineteen item checklist was finalized. It was so designed that it was "Do confirm type rather than a read do type". It was in three parts to be completed in three steps, first before induction of anesthesia, second before the incision and the third before the patient leaves the OR on completion of the procedure. All the issues of concern mentioned earlier which contributed to lack of safety in the OR were addressed.

The checklist is reproduced below:

\section{A. Before Induction of Anesthesia}

1. Has the patient confirmed his / her identity, site, procedure an d consent?

2. Is the site marked?

3. Is the anesthesia machine and medication check complete?

4. Is the pulse oximeter on the patient and functioning?

5. Does the patient have a known allergy?

6. Difficult airway or aspiration risk? If yes, is equipment and assistance available?

7. Risk of blood loss - if $>500 \mathrm{ml}$ or $7 \mathrm{ml} / \mathrm{kg}$ in children, have two IV lines and central access and fluids been planned? 


\section{B. Before skin incision}

8. Confirm team members have introduced themselves by name and role

9. Confirm the patients name, procedure and where the incision will be made

10. Has antibiotic prophylaxis been given within last 60 minutes?

\section{Anticipated critical events}

\section{To Surgeon}

a. What are the critical and non-routine steps

b. How long will the case take

c. What is the anticipated blood loss

12. To Anesthetist

- Are there any patient specific concerns

13. To Nursing tem

- Has sterility (including indicator results ) been confirmed

- Are there equipment issues or any concerns

14. Is essential imaging displayed

\section{Before patient leaves the operating room Nurse verbally confirms}

15. Name of the procedure

16. Completion of instrument, sponge and needle counts

17. Specimen labeling (read specimen labels aloud including patient's name)

18. Were there are any equipment problems to be addressed?

19. To Surgeon, Anesthetist and Nurse:

- What are the key concerns for recovery and management of this patient?

Having finalized the checklist, the WHO team did a pilot study in eight hospitals which were geographically and economically disparate, so that they form a representative sample. Four of these hospitals were from high income countries and four from mid and low income countries. The hospitals chosen are shown below:

Four High Income countries

- UWMC (USA)

- Toronto GH (Canada)

- St Mary's Hospital (London)

- Auckland City Hospital (New Zealand)

- Four Low / middle income countries

- Philippines GH (Manila, Philippines)

- Prince Hamza Hospital (Jordan)

- St Stephen's Hospital (Delhi, India)

- St Francis Hospital (Tanzania)

Basal statistics were collected from these hospitals over a three month period in spring, 2008. Following education and counseling of all involved health care personnel on the checklist, the checklist was implemented. The study extended over a six month period. There were a total of 3733 patients in the pre checklist period and 3955 patients after the checklist. Six outcome measures were used by direct observation to ensure that the checklists were being consistently applied. These outcome measures were

- Objective evaluation and documentation of airway before anesthesia

- Use of pulse oximetry at anesthesia

- Presence of two IV catheters or a central line before incision when estimated blood loss $>500 \mathrm{ml}$.

- Prophylactic antibiotics within one hour of surgery

- Oral confirmation before incision of

- Identity of patients

- Operation site 
- Procedure to be performed

- Sponge count at end

- The mean values of improvement in these test measures is shown in following table which is a condensation of the original published by Haynes et al (15).

\begin{tabular}{|l|c|c|c|}
\hline Process measure & Before & After & p \\
\hline Airway evaluation & 64.0 & 77.2 & $<0.001$ \\
\hline Pulse oximeter & 93.6 & 96.8 & 0.001 \\
\hline Venous access & 58.1 & 63.2 & $<0.001$ \\
\hline Prophylactic Antibiotic & 56.1 & 82.6 & $<0.001$ \\
\hline Patient ID and site & 54.4 & 92.3 & $<0.001$ \\
\hline Sponge count & 84.6 & 94.6 & $<0.001$ \\
\hline All & 34.2 & 56.7 & \\
\hline
\end{tabular}

There had been significant improvement in all measures except for obtaining venous access in patients with estimated large volume blood loss.

The parameters selected for assessment of improvement by institution of the checklist were

a. Rate of surgical site infection

b. Rate of unplanned return to the OR for complications

c. Incidence of pneumonia

d. Mortality rate and

e. Complication rate.

Significant improvement was seen at most of the sites regarding most of the parameters although the extent of improvement was different in different hospitals.

The mean results are shown in the following table which is a condensation from the original as reproduced by Haynes et al (15).

\begin{tabular}{|l|c|c|c|}
\hline Parameter & Before (\%) & After (\%) & p \\
\hline Surgical site infection & 6.2 & 3.4 & $<0.001$ \\
\hline Unplanned return to OR & 2.4 & 1.8 & $=0.47$ \\
\hline Pneumonia & 1.1 & 1.3 & $=0.03$ \\
\hline Death & 1.5 & 0.8 & $<0.001$ \\
\hline Any complications & 11.0 & 7.0 & \\
\hline
\end{tabular}

Although significant only for two parameters overall, a trend towards improvement in all parameters is evident. The only uncertainty of this study was whether the improvement was a true event or a Hawthorne effect due to observation. 
It was also not a randomized control study. However, the feasibility of implementation of the checklist across hospitals in all countries was proved. Subsequently by 2009 , more than 12 countries had enrolled in the program including $10 \%$ of all American Hospitals.

\section{REFERENCES}

1. Weiser TG, Regenbogen SE, Thompson KD et al.An estimation of the global volume of surgery: a modeling strategy based on available data.Lancet 2008;372:139-44.

2. Gawande A. The checklist manifesto - how to get things right.New Delhi,Penguin Books, 2009.

3. Debas HT, Gosselin R, McCord C et al.Surgery.In: Jamison DT, Breman JG, Measham AR, Alleyne G, Claeson M, Evans DB, Jha P, Mills A, Musgrove P, editors. Disease Control Priorities in Developing Countries. 2nd edition. Washington (DC): World Bank; 2006. Chapter 69.

4. Hales BM, Pronovost PJ.The checklist--a tool for error management and performance improvement.J Crit Care 2006;21:231-5.

5.PJ Pronovost. Needham D, Berenholtz $\mathrm{S}$ et al. An intervention to reduce catheter related blood stream infection in the ICU.New Eng $\mathrm{j}$ med 2006;355:2725-32

6.Luby SP, Agboatwalla M, Feikin DR et al. Effect of handwashingon child health: a randomized control trial.Lancet 2005;366:225-33.

7. Lindenauer PK, Remus D, Roman S et al. Public reporting and pay for performance in hospital quality improvement. N Engl J Med 2007;356:486-96

8. Youngson GW, Flin R. Patient safety in Surgery: non-technical aspects of safe surgical performance. 2010,4:4, http://www.pssjopunal. com/content $/ 4 / 1 / 4$

9. ElBardissi AW, Regenbogen SE, Greenberg CCet al Communicationpractices in four Harvard Surgical services: a surgical safety collaborative. Ann Surg 2009;250:861-5

10.Burda SA, Hobson D, Pronovost PJ. What is the patient really taking? Discrepancies between surgery and anesthesiology preoperative medication histories. QualSaf Health Care 2005;14:414-6.

11.Makary MA, Mukherjee A, Sexton JB et al Operating room briefings and wrong site surgery. J Am Coll Surg. 2007;204:236-43.

12.Lingard L, Espin S, Rubin B et al. Getting teams to talk: development and pilot implementation of a checklist topromote interprofessional communication in the OR.

13.QualSaf Health Care 2005; 14:340-6.Lingard L, Garwood S, Poenaru D. Tensions influencing operating room team function: does institutional context make a difference? Med Educ 2004; 38:691-9.

14.Mazzocco K, Petitti DB, Fong KTet al Surgical team behaviors and patient outcomes. Am J Surg 2009;197:678-85

15.Haynes AB, Weiser TG, Berry WR et al. A surgical safety checklist to reduce morbidity and mortality in a Global population. 16.N Engl J Med 2009;360:491-9. 